\title{
The generation of stable project plans
}

\author{
Roel Leus \\ Fund for Scientific Research - Flanders (Belgium) (F.W.O.-Vlaanderen), Department of Applied Eco- \\ nomics, Katholieke Universiteit Leuven, Naamsestraat 69, 3000 Leuven, Belgium \\ (e-mail: roel.leus@econ.kuleuven.ac.be)
}

Received: October 2003

\begin{abstract}
This text summarises the PhD thesis that Roel Leus presented to obtain the degree of Doctor in Applied Economics at the Katholieke Universiteit Leuven, in September 2003. The promotor of the thesis was professor Willy Herroelen. The thesis is written in English and is available from the author's website. ${ }^{1}$ The goal of the thesis was to provide recommendations for the detailed scheduling of multiproject organisations, when a certain degree of uncertainty exists about a number of characteristics of the project. Up till now, the majority of the literature on project scheduling has consisted of deterministic models for planning a single project: both the uncertainty aspect as well as the intrinsic difficulty of coordination of a portfolio of projects have been largely ignored.
\end{abstract}

Key words: Project scheduling, uncertainty, robustness, multi-project organisations

MSC classification: 09B35, 90B36

\section{Introduction and general outline}

Projects in a multi-project organisation are interdependent, primarily because they use a joint pool of resources. The central theme of the PhD thesis of Leus (2003) is the concept of stability, a quality that is associated with a schedule when this schedule is able to suppress propagation of disruptions, both within the individual project as well as towards other projects. In this way, we attempt to obtain a maximum degree of independence between and within individual project schedules. Stability is a specific form of robustness: a robust schedule is protected as well as possible against uncertain events that can occur during the execution of the project

1 http://www.econ.kuleuven.ac.be/tew/academic/prodbel/people/Roel/ 
- some examples are bad weather conditions, illness of workers, changing project specifications, ...

The aim of the thesis was to formulate recommendations for the detailed scheduling of multi-project organisations when a certain degree of uncertainty exists about a number of characteristics of the project. We have especially focused on the problem of scheduling projects when stochastic durations are assigned to the individual project activities. Up till now, the majority of the literature on project scheduling has consisted of deterministic models for scheduling a single project, and both the uncertainty aspect as well as the intrinsic difficulty of coordination of a portfolio of projects have been largely neglected: various authors consider multi-project scheduling simply as the scheduling of one large project with as sole objective the construction of a feasible plan with minimum length. However, the different projects that are ongoing in parallel at any particular moment have differing objectives and are each evaluated separately on the way in which they live up to these objectives - every project has separate deliverables and will be evaluated based on the timeliness, quality and cost of those deliverables.

This qualitative insight is the starting point of the thesis and we have tried to translate this intuition into a number of technical scheduling and resource allocation models that allow to focus attention on quantitative implications on the time dimension of project performance. The central idea is that, although we normally desire to complete each project by itself as quickly as possible, we sometimes have to make concessions for reasons of coordination and broader organisational goals. This is achieved by implicit or explicit insertion of small 'buffers' at various places throughout the scheduling horizon. In this way, an integrated plan that covers the different projects is most valuable.

\section{Structure and detailed contents of the text}

The first chapter of the text provides a general introduction to project planning and draws some parallels between project planning and job shop planning. One of the main lessons to be learnt is that scheduling resources to $100 \%$ utilisation will inevitably lead to major delays and queuing when only the slightest amount of uncertainty is present (cfr., Adler et al. 1995, 1996 and Levy and Globerson 1997).

The second part of the thesis (Chapt. 2) presents a classification and survey of the literature on single-project planning with uncertainty, attempting to put order to the vast number of articles that do not always explain how they fit in with the mostly unorganised existing body of research. Most of the material in this chapter can also be found in Herroelen and Leus (2003a).

A third part of the thesis is devoted to the development of stable schedules, with the minimisation of expected deviations in starting times as objective. This work is the most technical part of the text and encompasses Chapts. 3, 4 and 5 (this material is also available as Herroelen and Leus 2003b, Leus and Herroelen 2002 and Leus and Herroelen 2003). Exact algorithms and complexity analysis are provided, 
and we also examine the associated problem of resource allocation, again geared especially towards guaranteeing stability. We have not proposed solutions to joint scheduling and resource allocation decisions, but we have pointed out why such integrated solutions are very hard, both from mathematical and managerial points of view. Chapter 3 and part of Chapt. 4 investigate the development of schedules that anticipate one or a minor number of disruptions. This is applicable when the number of disruptions is limited (as opposed to a chaotic environment, where planning is not management's primary concern, but rather 'fire-fighting' and variability reduction). Single-disruption models are especially appropriate for project scheduling because the extensive use of human resources makes it possible to actively prevent cumulation of disruptions, whereas machine resources will have independent stochastic breakdowns. Chapter 5 examines detailed resource allocation, which is performed after scheduling has taken place, in line with the hierarchical planning framework of De Boer (1998).

The fourth part of this text is an extensive study of the 'Critical Chain' methodology for project management (CCPM), proposed by Goldratt (1997) (results of our study of the merits and pitfalls of CCPM have been published in Herroelen and Leus 2001 and Herroelen et al. 2002; we also refer the reader to Elmaghraby et al. 2003). The methodology offers valuable insights for the management of project environments with variable activity durations. It is recognised that duration estimates of activities are very important, since stochastic quantities are essentially captured by a single deterministic value. From an analysis of the behaviour of human resources, it is concluded that individual activity duration estimations regularly contain protection from variability. The problem is that this protection is not clearly visible or even identified, and often wasted. CCPM advocates the use of aggressive duration estimates (median or average durations) and the explicit inclusion of protection time at strategic places in the schedule, which can be actively monitored and controlled. In line with de Boer (1998), it is advocated that 'slack' be used in a controlled way: it must be quantified and made visible to management.

Unfortunately, scheduling issues are not allotted an appropriate role in most of the sources describing the CCPM-methodology. Those sources spend a lot of time explaining variability and stochastics, which is a good thing, but they do not give enough attention to the combinatorial implications of resource constraints, the very aspect the method is meant to tackle in the first place, the 'critical chain' being a 'resource-constrained critical path'.

Finally, a fifth part of this thesis has attempted to propose planning solutions for multi-project environments on the basis of the experience gained in the preceding pieces of the text. This synthesis contains a classification of multi-project planning environments and provides hints as to which situations are best served by which planning techniques, including guidelines for the choice between stable and active schedules. A short version of this part of the text also appears in Herroelen and Leus (2003c). 


\section{References}

Adler PS, Mandelbaum A, Nguyen V, Schwerer E (1995) From project to process management: an empirically-based framework for analyzing product development time. Management Science 41(3): 458-484

Adler PS, Mandelbaum A, Nguyen V, Schwerer E (1995) Getting the most out of your product development process. Harvard Business Review (March-April issue): 134-152

De Boer R (1998) Resource-constrained multi-project management. PhD Thesis. University of Twente, The Netherlands

Elmaghraby SE, Herroelen W, Leus R (2003) Note on the paper 'Resource-constrained project management using enhanced theory of constraint' by Wei et al. International Journal of Project Management 21: 301-305

Goldratt EM (1997) Critical chain. The North River Press Publishing Corporation, Great Barrington

Herroelen W, Leus R (2001) On the merits and pitfalls of critical chain scheduling. Journal of Operations Management 19: 559-577

Herroelen W, Leus R (2003a) Project scheduling under uncertainty: survey and research potentials. European Journal of Operational Research (forthcoming)

Herroelen W, Leus R (2003b) The construction of stable project baseline schedules. European Journal of Operational Research (forthcoming)

Herroelen W, Leus R (2003c) Robust and reactive project scheduling: a review and classification of procedures. International Journal of Production Research (forthcoming)

Herroelen W, Leus R, Demeulemeester E (2002) Critical chain project scheduling: do not oversimplify. Project Management Journal (December issue): 48-60

Leus R (2003) The generation of stable project plans. Complexity and exact algorithms. PhD Thesis. Department of Applied Economics, Katholieke Universiteit Leuven, Belgium (Available from the website http://www.econ.kuleuven.ac.be/tew/academic/prodbel/people/Roel/)

Leus R, Herroelen W (2002) The complexity of generating robust resource-constrained baseline schedules. Research report 0250. Department of Applied Economics, Katholieke Universiteit Leuven, Belgium

Leus R, Herroelen W (2003) Stability and resource allocation in project planning. IIE Transactions (forthcoming)

Levy N, Globerson S (1997) Improving multiproject management by using a queuing theory approach. Project Management Journal (December issue): 40-46 